\title{
The Pilates method improves the relationship agonist-antagonist flexor and extensor knee in elderly: a randomized controlled trial
}

\section{O método Pilates melhora a relação agonista-antagonista dos extensores e flexores do joelho em idosas: um ensaio clínico randomizado e controlado}

\author{
Laís Campos de Oliveira', Raphael Gonçalves de Oliveira', Deise Aparecida de Almeida Pires-Oliveira
}

\begin{abstract}
Introduction: Due the increase in elderly population, a increase concern in considering factors that can contribute to healthy aging. The muscle strength of the lower limbs and the improvement of the agonist-antagonist relationship and knee extensor and flexors, enable greater independence in older people. Objective: To investigate the effects of Pilates method in agonist-antagonist relationship in knee extensor and flexor in healthy older women. Methods: Thirty-two elderly woman were randomly divided into two groups. Experimental group ( $E G, n=16,63.62 \pm 1.02$ years) and control group (CG, $n=16,64.21 \pm 0.80$ ). Isokinetic evaluation of the knee extensors and flexors was held at $180 \%$ s, pre and post-intervention, considering the agonist-antagonist ratio (\%). The experimental and control groups participated of Pilates sessions and static stretching, respectively, twice a week for 12 weeks. To verify the normality of the data was used the Shapiro-Wilk test followed by the Student $t$ test to compare the differences between the pre and post evaluation $(p<0.05)$. Results: It was possible to identify a statistically significant improvement in agonist-antagonist relationship between the pre and post-intervention only for the GE $(p<0.005)$ for both the right lower limb and for left lower limb. Conclusion: The Pilates method improves the relationship agonist-antagonist of the knee extensor and flexor muscles after 12 weeks of intervention. Registro Brasileiro de Ensaios Clínicos: RBR-472p29.
\end{abstract}

Keywords: Elderly; Physical exercise; Muscle strength.

\section{RESUMO}

Introdução: Com o aumento da população idosa, cresce a preocupação em considerar fatores que possam contribuir com um envelhecimento saudável. A força muscular dos membros inferiores e a melhora da relação agonista-antagonista dos extensores e flexores do joelho, possibilitam uma maior independência em pessoas idosas. Objetivo: Verificar os efeitos do método Pilates na relação agonista-antagonista dos extensores e flexores do joelho em mulheres idosas saudáveis. Método: Trinta e duas idosas foram subdivididas aleatoriamente em dois grupos. Grupo Experimental ( $G E, n=16,63,62 \pm 1,02$ anos) e Grupo Controle $(G C, n=16,64,21 \pm 0,80)$. Avaliação isocinética dos extensores e flexores do joelho foi realizada a $180 \%$, pré e pós-intervenção, considerando-se a relação agonista-antagonista (\%). O GE e GC participaram de sessões de Pilates e de alongamento estático, respectivamente, duas vezes por semana, durante 12 semanas. Para verificar a normalidade dos dados foi utilizado o teste de Shapiro Wilk, seguido do teste $t$ de Student para comparar as diferenças entre a pré e a pós avaliação $(p<0,05)$. Resultados: Foi possível identificar uma melhora estatisticamente significativa da relação agonista-antagonista entre a pré e a pós-intervenção apenas para o $G E(p<0,005)$, tanto para o membro inferior direito, quanto para o esquerdo. Conclusão: O método Pilates melhora a relação agonista-antagonista dos músculos extensores e flexores do joelho de idosas, após 12 semanas de intervenção. Registro Brasileiro de Ensaios Clínicos: RBR-472p29.

Palavras-chave: Idoso; Exercício físico; Força muscular.

Corresponding Author: Deise Aparecida de Almeida Pires-Oliveira. Rua Marselha 591, Bairro Jardim Piza, Zip COde: 86041-140, Londrina (PR), Brasil. Phone: 43 - 3371 7339/ 3371 9849. E-mail: deisepyres@gmail.com

${ }^{1}$ Universidade Norte do Paraná (UNOPAR), Londrina (PR), Brazil.

Financial support: None.

Submission date 24 February 2015; Acceptance date 12 May 2015; Online publication date 20 May 2015 


\section{INTRODUCTION}

The number of elderly has considerably increased worldwide. ${ }^{(1,2)}$ Every decade, the average life expectancy at birth, grew by three years approximately. ${ }^{(3)}$ In Brazil, it is estimated that by the year 2025 , the elderly population will be around 30 million. ${ }^{(4,5)}$

This growth will lead to increased concern of health professionals, to contribute to a healthy and independent old age, in order to preserve or improve the functional autonomy of these people, so that, they can grow old with a higher quality of life. ${ }^{(6-8)}$

A process that occurs at this stage of life and can harm healthy aging is sarcopenia, which leads to loss of muscle strength, predominantly in the lower limbs, and the quadriceps muscle, the more committed on aging..$^{(9)}$ In this case, quadriceps muscle strength, when decreased, creates muscular imbalance in agonist-antagonist relationship flexor and extensor knee muscles and can contribute to a higher incidence of falls, fractures and functional limitations. ${ }^{(9-12)}$

For prevention and/or improved muscular balance between the extensor and flexor muscles of the knee, some of exercise options have been used as an effective way, contributing to the increase in muscle mass, the force levels and agonist-antagonist relationship in population elderly. ${ }^{(13-16)}$ In this way, you can preserve the functional autonomy levels and consequently increase the independence in performing daily living activities. ${ }^{(17,18)}$

An option of exercise, which recently has been investigated in several populations, is the Pilates method. ${ }^{(19-23)}$ These exercises may be carried out in equipment suitable for practicing the method which make use mainly springs provide resistance; or on the ground, with the use of accessories such as ball and elastic bands. ${ }^{(22)}$ The Pilates method, carried out systematically, may be an option for the development of strength and improves muscle balance of the knee extensors and flexors in elderly. ${ }^{19,23-25)}$

Traditionally, every Pilates session are performed stretching and strengthening exercises for the main body segments (lower and upper limbs and trunk). However, research on the method, have focused primarily on the effects on flexibility, strengthening muscles responsible for stabilizing the spine, posture and breathing, ${ }^{(21)}$ existing in this way, a lack of studies that have checked the effects of the Pilates method, based on the balance of agonist-antagonist relationship of the lower limbs in the elderly.

In view of the increased demand for Pilates as a form of exercise for older people and due to the absence of studies that have found the influence of this method on the balance between the hamstrings, quadriceps elderly muscles, the advent of surveys have aimed at observing the influence of these variables are fundamental.

Once the Pilates provides resistance training, all the major muscle groups of the body ${ }^{(17,18)}$ including the extensor and flexor muscles of the knee ${ }^{(26)}$ important for greater functional independence; the aim of this study is to test the hypothesis that the Pilates method, can improve the agonist-antagonist relationship of flexor and extensor of the knee in elderly woman.

\section{METHODS}

This study was a clinical trial, randomized controlled trial with elderly residents in the community of the city of Jacarezinho, Parana, Brazil. It followed the ethical standards set forth in the Declaration of Helsinki (1975, revised in 1983). The study was approved by the Ethics Committee for Research involving human subjects of the Universidade Norte do Paraná (Brazil) under the protocol 513001 and registered in the Brazilian Registry of Clinical Trials as registration number: RBR-472p29. The sample size was determined using as a basis for calculation, the peak isokinetic torque presented by previous study, ${ }^{(27)}$ taking into account an error of $20 \%$ and $\alpha$ value of 0.05 , so it was identified the need of 16 participants in each group.

Inclusion criteria were: a) age between 60 and 65 years; b) female; c) ability to perform activities of daily living without assistance (ADL and IADL); d) body mass index (BMI) within the normal range for their age (between $22: 27 \mathrm{~kg} / \mathrm{m2})^{(28)}$; e) medical certificate stating fitness to practice physical exercises; f) are not practicing any kind of physical exercise in the last six months; $g$ ) agree to do not practive any other type of exercise during the research.

Exclusion criteria were: a) cognitive impairment $<19$ according to the Mini Mental State Examination (MMSE) ${ }^{(29)}$; b) functional limitations in walking or the use of assistive devices (cane, walker and crutches); c) affirmative answer to any question, a questionnaire to identify comorbidities related to severe visual problems, osteoarthritis of the knees or hips, orthopedic surgeries of the hip, knees or ankles.

The elderly who met the inclusion/exclusion, 32 were included in the survey. All were fully informed of the objectives and methodology of the study and subsequently signed informed consent form.

After the initial selection, the volunteers were underwent to evaluation of isokinetic muscle strength of the extensor and flexor muscles of the knee, to 180 degrees per second $(180 \% \mathrm{~s})$, so it could be observed agonist-antagonist relationship of these muscles. Subsequently, the randomization process occurred by means of a table of random numbers, generated by a computer, which distributed the volunteers into two groups (experimental and control), with 16 individuals each. The experimental group (EG) held Pilates exercises, while the control group (CG) conducted exercise static stretching. In both groups were chosen exercises 20 covering the main body segments (lower and upper limbs and trunk), in 60 minute sessions twice a week for 12 weeks; He was respected for at least two days between sessions. After the speeches, the 
elderly women were reassessed by the same professional (assessor blinded to the formation of groups) that had conducted the pre-intervention assessment. Figure 1 illustrates the sequence of events.

\section{Isokinetic evaluation of the knee extensors and flexors}

Muscle strength test, the extensors and flexors of the knee was performed with the isokinetic dynamometer Biodex System 4.0 (Biodex Medical Systems, Shirley, NY) before and after the intervention period.

Preceding the test, the device was calibrated following the manufacturer's standards. The warm up was conducted in an upright exercise bike with light load (25 watts) and comfortable speed (40 rpm) for five minutes. Further, the evaluator explained in detail the testing procedures and voluntary positioned on the seat of the equipment, with the angle of the seat to 120 degrees of flexion.

The dynamometer arm rotational axis was aligned with the lateral epicondyle right lower limb femoral (RLL).
The local application of force was positioned approximately two centimeters of the medial malleolus. Belts were fixed in the trunk, pelvis and thigh, in order to avoid compensatory movements. ${ }^{(30)}$ After a brief familiarization with the equipment and the range of motion, voluntary realized the extent of testing and knee flexion (concentric/concentric) at a rate of 180 degrees per second (180ㅇ/s), starting from a position where the knee joint was at 90 degrees of flexion. Three sets of five repetitions were performed, with 30 seconds rest between sets. ${ }^{(31)}$ The same procedure was then repeated on the left lower limb (LLL). The variable considered for the study was the relative agonist-antagonist of the extensor and flexors, knee, expressed in percentage (\%), which for speed of $180 \%$ s should be 70 to $80 \%$ in healthy adults. We have used as a reference value in other studies since there is no specific reference value for the elderly. ${ }^{\text {(32-34) }}$

The participants were instructed to perform maximal voluntary contraction strength of the knee extensors, followed immediately by the maximum contraction of the

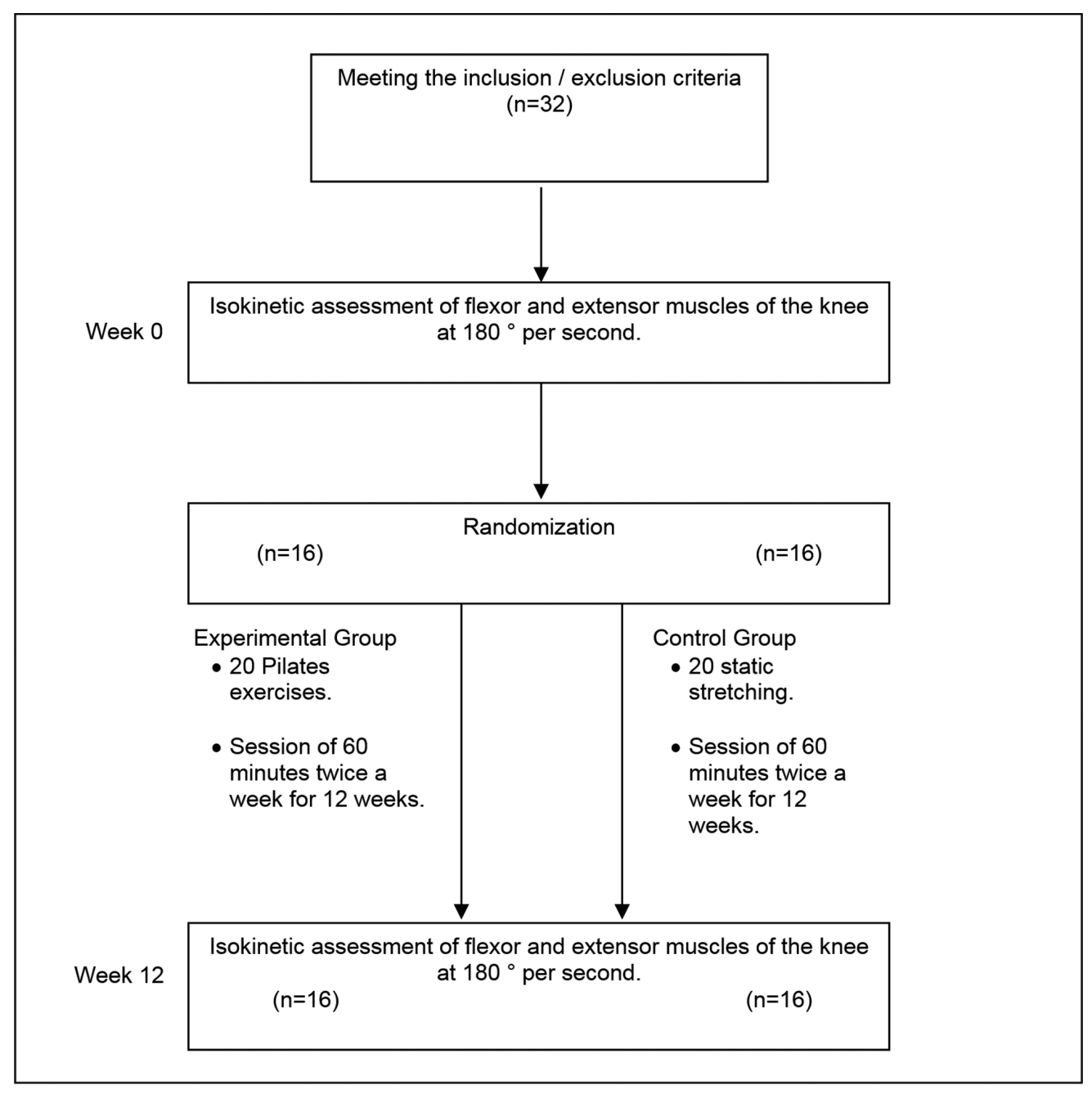

Figure 1. Diagram showing the development of the study. 
knee flexors, continuously. During the test were used words of encouragement, such as "harder" and "stronger".

\section{Intervention protocol}

\section{Experimental Group}

Interventions by the experimental group contained 24 Pilates sessions held twice a week for 12 weeks. Each intervention lasted 60 minutes. The first two sessions were used to familiarize the volunteers with Pilates, explanation and proper execution of each movement, as well as for greater understanding of the principles of the method.

Equipment used for the exercises were: Combo Chair, Cadillac Trapeze, Universal Reformer and Ladder Barrel (Instituto de Ortopedia e Fisioterapia, Sao Paulo, Brazil).

They selected 20 strengthening and stretching exercises for the main body segments (lower and upper limbs and trunk). The sequence of the exercises, the equipment used and the traditional name for each year of the Pilates method, were as follows: initial stretches on the Cadillac Trapeze (Spine Stretch, Mermaid, Stretching Knee), strengthening of the lower limbs in the Chair Combo (Footwork Double Leg Pumps Toes, Pumping One Leg, Pump One Leg Front, Achilles Stretch) and in the Cadillac Trapeze (Leg Series Supine Lowers, Leg Series Supine Circles), strengthening the flexor and extensor muscles of the trunk in the Cadillac Trapeze (Sit Up, Sit Up One Leg, The Hundred, Trunk Up, Body Extension), strengthening of the upper limbs in Reformer Universal (Arms Pulling, Arms Biceps, Arms Triceps), final stretching in the Universal Reformer (Front Splits, Stretching the Chain Posterior) and on Ladder Barrel (Stretch Back and Forward).

All exercises were performed in a series of ten repetitions. Exercise intensity was changed (the evolution of the charge was due to the change in the spring positioning equipment, or inability addition, through the spring return, by someone with greater resistance) as the evolution of the strength of the volunteers, keeping the number of repetitions and series. To determine the level of effort and consequently to changing loads, were used verbal descriptions as the Borg CR 10 scale:(35) light load (Borg $\leq 2$ ), moderate load (Borg $>2$ and $<5$ ), heavy load (Borg $\geq 5$ and $<7$ ) and near maximum load (Borg $\geq 7$ ). The stress level was maintained during sessions moderate (Borg between 3 and 4). Every time the intensity of the exercise was changed, the new load used was immediately noted in individual records, used for training log.

The exercises were selected in an attempt to improve muscle strength globally (with emphasis on the knee extensors and flexors). The volunteers were trained on the principles of the method (Center, Control, Concentration, fluidity, precision and breathing) that needed to be respected in the implementation of each year. ${ }^{(36)}$

The interventions were delivered by a professional certified in Pilates and experience with the method.

\section{Control Group}

This group during the 12-week intervention, made only of static stretching exercises in 24 sessions, lasting 60 minutes, held twice a week. Twenty exercises were performed for the following body regions: neck and upper limbs (upper trapezius, scalene, sternocleidomastoid, flexors and wrist extensors and fingers, deltoids, triceps and pectoral), side chain stretching and lower limbs (oblique, square lower back, hamstrings, adductors, glutes, abductors and sural triceps).

The exercises were carried out actively, with three series, held for 30 seconds each, with one minute rest between sets. The volunteers remained seated on mats Ethylene Vinyl Acetate (EVA), lying supine or standing, depending on the stretching exercise that was executed.

\section{All interventions were delivered by a skilled professional.}

\section{Statistical analysis}

Descriptive analysis of the data expressed as mean and standard deviation was performed. To see if there were differences between the groups with respect to baseline physical characteristics (age, weight, height and BMI), when pre-intervention, the Mann Whitney $U$ test was used. Check the normality of the data was carried out through the Shapiro-Wilk test. As normal distribution hypothesis was not rejected, we applied the Student t test for dependent samples to verify the pre- and post-intervention comparisons within groups. The confidence interval allowed in all tests was $95 \%$ $(p<0.05)$. Data were treated in Bioestat 5.3 program.

\section{RESULTS}

The initial physical characteristics of the volunteers showed no statistically significant difference $(p>0.05)$. Age ranged between 60 and 65 years, body weight between 54.2 and $69 \mathrm{~kg}$, height between 155 and $174 \mathrm{~cm}$ and BMI between 22.6 and $26.8 \mathrm{~kg} / \mathrm{m}^{2}$ (Table 1 ).

As for the agonist-antagonist relationship in EG there was significant difference pre and post-intervention to the right lower limb (before: $52.64 \pm 9.82$, and after: $62.16 \pm 12.11, p=0.005$ ) and left (before: $56.23 \pm 8.63$, and after: $62.10 \pm 9.99, p=0.014)$. In the control group was no statistical difference for both the right lower limb (before:

Table 1. Mean, standard deviation and alpha value $(p)$ of the initial physical characteristics (pre-intervention time) in the experimental group and control.

\begin{tabular}{crcc}
\hline Pre & EG $(\mathbf{n}=\mathbf{1 6})$ & CG $(\mathbf{n}=\mathbf{1 6})$ & p \\
\hline Age (years) & $63.62 \pm 1.02$ & $64.21 \pm 0.80$ & 0.124 \\
Weight $(\mathrm{Kg})$ & $64.56 \pm 2.06$ & $64.71 \pm 2.58$ & 0.851 \\
Height $(\mathrm{cm})$ & $161.93 \pm 4.56$ & $160.71 \pm 4.93$ & 0.755 \\
BMI $\left(\mathrm{Kg} / \mathrm{m}^{2}\right)$ & $24.71 \pm 1.36$ & $25.08 \pm 1.26$ & 0.466 \\
\hline
\end{tabular}

$\mathrm{BMI}=$ Body Mass Index. 


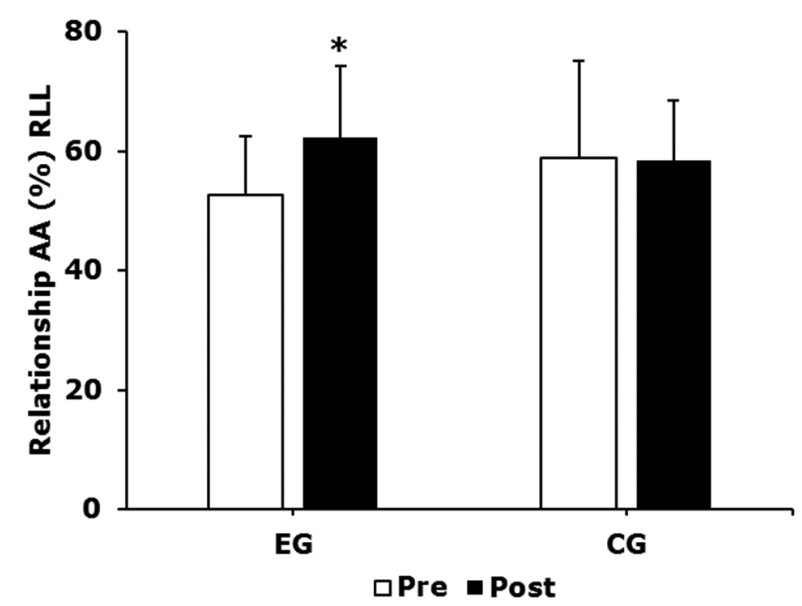

Figure 2. Agonist-antagonist (AA) relationship of the right lower limb (RLL). Pre and post-intervention results of the experimental group ( $E G, N=16)$ and control group $(C G, N=16)$. Values are mean $\pm S D$. $* P<0.05$ compared to pre-intervention in $\mathrm{EG}$.

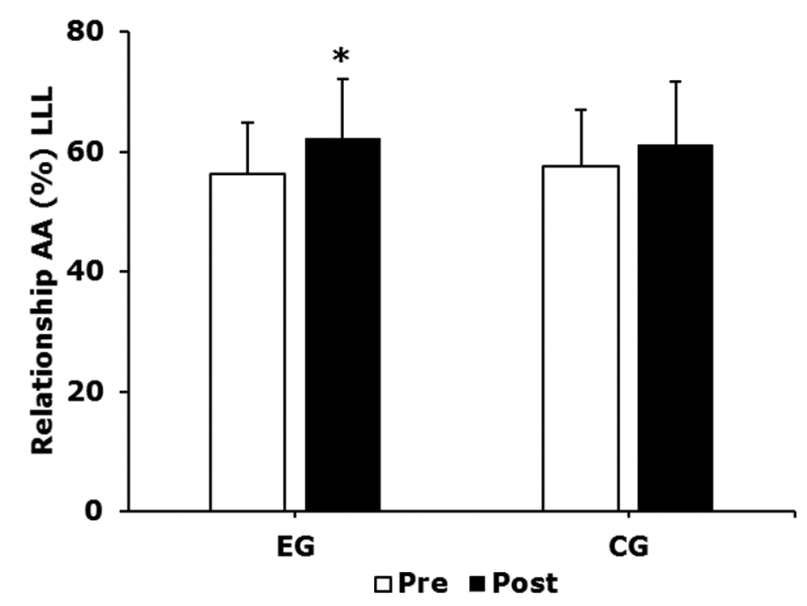

Figure 3. $R$ Agonist-antagonist (AA) relationship of the left lower limb (LLL). Pre and post-intervention results of the experimental group (EG, $N=16$ ) and control group ( $C G, N=16)$. Values are mean $\pm S D$. $* P<0.05$ compared to pre-intervention in EG.

$58.80 \pm 16.33$, and after: $58.47 \pm 10.05, p=0.936)$, and to the left (before: $57.60 \pm 9.41$, and after: $61.18 \pm 10.42$, $p=0.112$ ). Figures 2 and 3 show the pre and post-intervention comparison between experimental and control groups to the lower right and left limbs respectively.

\section{DISCUSSION}

The Pilates method has been increasingly chosen as a way to exercise the elderly population, which reinforces the need to be better investigated ${ }^{(36)}$ The research on the method have focused primarily on observing the following variables: Flexibility, muscle strength the stabilizers of the spine, improves posture and balance. ${ }^{(21,23,24)}$ currently, has been investigated the influence of the Pilates method in muscle strength of the extensors and flexors elderly knee, ${ }^{(26)}$ due to its importance for greater functional independence. However, little is known about the Pilates method's performance in improving the agonist-antagonist relationship, flexor and extensor knee this population.

The agonist-antagonist relationship occurs when some muscles act in directions opposite, enabling specific joint movements. In the knee joint, for example, to occur a certain movement, the hamstrings and quadriceps, contract while promoting joint stability and muscle. Knee, when analyzed agonist-antagonist relationship, it is observed specifically muscle action between hamstrings-quadriceps. ${ }^{(35)}$

When do you assess this relationship through an isokinetic dynamometer, it is considered ideal, the relative value of 70 to $80 \%$ to be used to speed of $180 \%$ s (evaluation of muscle strength). ${ }^{(32-34)}$ Some research show that larger or smaller differences than 10 to $15 \%$ of the reference value in the knee agonist-antagonist ratio, are considered relevant. (37) These differences indicate a muscle imbalance, predisposing the various lesions and thereby decrease the function and disability, particularly in the elderly. ${ }^{(38,39)}$

The results of our study showed a significant difference $(p<0.05)$ between the pre and post-intervention assessments, to improve the agonist-antagonist relationship, flexor and extensor of the knee elderly, who underwent 12 weeks intervention with Pilates, twice per week (EG). While the same did not occur with CG, who held the same time, intervention with static stretching.

Other studies ${ }^{(22-26)}$ who used Pilates as a form of muscle strengthening, not verified the agonist-antagonist relationship of the hamstrings, quadriceps muscles. However, there are some research ${ }^{(40,41)}$ who used other types of exercise, and found that the agonist-antagonist relationship of the hamstrings, quadriceps muscles. In a study by Karatrantoua et al. ${ }^{(40)}$ with 26 moderately active women, it observed the effects of whole body vibration exercise (vibrating platform), in improving hamstring-quadriceps ratio. The volunteers were divided into whole body vibration group (EG), who underwent eight weeks of intervention, three times a week, and control group (CG) who do not carry out any intervention. The results showed improvement in hamstring-quadriceps ratio in EG, and can also be observed in our study.

In a study by Lopes et al. ${ }^{(41)}$ analyzed the effects of strengthening exercises classes and muscle stretching, for various body segments on the hamstrings, quadriceps relationship, checking the muscular balance in 68 active elderly. The elderly exercises performed for more than one year, while maintaining a frequency of twice a week. It was observed the existence of muscle imbalance in the hamstrings, quadriceps ratio, most elderly women, showing the need to perform strengthening exercises of the extensors and knee flexors for this study population.

This imbalance in agonist-antagonist relationship flexor and extensor of the knee elderly, ${ }^{(41)}$ appears as a hypothesis, the 
choice of muscle strengthening exercises of the lower limbs and the number of exercises which the volunteers performed. In our study, CG, performed muscle stretching exercises for the whole body, for three months and also did not change in agonist-antagonist relationship flexor and extensor knee.

The improvement observed in our study on the relationship agonist-antagonist flexor and extensor knee for $E G$, it is assumed that it is the choice of Pilates exercises (especially those aimed at the strengthening of the lower limbs), selected for the protocol of this study (Footwork Double Leg Toes Pumps, Pumping One Leg, Pump One Leg Front, Achilles Stretch, Supine Leg Series Lowers, Supine Leg Series Circles). Once the Pilates method enables a wide variety of exercises, professional, during Pilates sessions, should pay special attention to the priorities presented by each practitioner, especially with regard to the choice of exercises.

Another important factor that should be highlighted is the concern with the evolution of the load. Programs whose purpose is to check the effects of training on improving muscle strength, control the intensity of the effort, becomes fundamental. ${ }^{(42,43)}$ Research $^{(19,22,23)}$ using the Pilates method as a form of exercise typically leaves the professional judgment administering the Pilates, the subjective perception to the evolution of the load, as the verification of possible compensation (error in the execution of the movement), by the performer. For the present study, notes were held in individual records of training, which guided the evolution of charge, through verbal descriptions, as proposed by Borg CR10, ${ }^{(35)}$ which enabled tighter control of this variable. This may also have contributed to the improvement in the relationship agonist-antagonist extensor and flexor muscles of the knee, the elderly belonging to EG.

In this study, the evolution of the load took place by the spring positioning of the change in equipment or inability addition, through the spring return, by someone with greater resistance. Mello et al. ${ }^{(44)}$ demonstrated that the resistance torque provided by the springs during the movement, can vary depending on these two factors (such positioning equipment or resistance level provided by the same). The resistance torque is changed even during execution of the movement as the spring elongates, providing different voltages along the same movement. Factors to be considered in prescribing and evolution of Pilates intervention protocols, with the use of equipment.

Other studies using the intervention with the Pilates method must be performed in order to be seen whether this exercise option contributes to the improvement of balance in this relationship agonist-antagonist flexors and knee extensors in the elderly, as well as, improve compared to other body segments, and other population, thus contributing to the discussion of this theme understudied. Specifically Pilates, requires special attention in the choice of exercises and factors that may influence the progression of muscle strengthening.
This study specifically evaluated the improvement of the relationship of the agonist-antagonist extensor muscles and knee flexors, however, the intervention protocol consisted of exercises for the major body segments, as traditionally worked in clinical practice. However, greater emphasis was given to the lower limbs, which possibly contributed to the improvement of the hamstrings, quadriceps muscle balance.

Once seniors have characteristics that compromise the relationship of the agonist-antagonist extensor and flexor muscles of the knee, the Pilates method can be an effective form of exercise to improve balance these muscles. Thus damage can be avoided in the functionality of the elderly, which predisposes to injury and dependence to perform daily activities.

\section{CONCLUSION}

The Pilates method improved the agonist-antagonist relationship of the extensor and flexor muscles of the knee in healthy elderly when subjected to 12 weeks of intervention, can be considered when prescribing exercise for this purpose.

\section{AUTHORS CONTRIBUTION}

DAAPO prepared the research project and defined the study design, contributed to the drafting of the text and approved the final version. LCO conducted the intervention of the study, contributed to the drafting of the text and approved the final version. RGO participated in the definition of the study design, performed the statistical analysis, contributed to the drafting of the text and approved the final version. All authors read and approved the final manuscript.

\section{COMPETING INTERESTS}

The authors declare no conflicts of interest.

\section{REFERENCES}

1. Christensen K, Doblhammer G, Rau R, Vaupel JW. Ageing population: the challenges ahead. The Lancet 2009;374(9696):1196-1208.

2. Gomes I, Nogueira EL, Engroff P, Ely LS, Schwanke CHA, Carli GAD, Resende $\mathrm{TL}$. The multidimensional study of the elderly in the Family health strategy in Porto Alegre, Brazil (EMI - SUS). Pan Am J Aging Res 2013;1(1):20-24.

3. Jagger $C$, Matthews R, Lindesay J, Robinson T, Croft P, Brayne $C$. The effect of dementia trends and treatments on longevity and disability: a simulation model based on the MRC Cognitive Function and Ageing Study (MRC CFAS). Age Ageing 2009;38(3):319-325.

4. Figueiredo CF, Assis MG, Silva SLA, Dias RC, Mancini MC. Functional and cognitive changes in community-dwelling elderly: Longitudinal study. Braz J Phys Ther 2013;17(3):297-306.

5. Rocha LM, Miró A, Schneider RH, Silva, IG, Schwanke CHA. An overview about geriatrics and aging in Brazil. Neurol Psychiatr Geriatr 2010;10(59):220-224.

6. Akishita M, Ishii S, Kojima T, Kozaki K, Kuzuya M, Arai H, Arai H, Eto M, Takahashi R, Endo H, Horie S, Ezawa K, Kawai S, Takehisa Y, Mikami H, Takegawa S, Morita A, Kamata M, Ouchi Y, Toba K. Priorities of health care outcomes for the elderly. J Am Med Dir Assoc 2013;14(7):479-484.

7. Oeseburg B, Hilberts R, Luten TA, Etten AVM, Slaets JPJ, Roodbol PF. Interprofessional education in primary care for the elderly: a pilot study. BMC Med Educ 2013;13:161. 
8. Siewert U, Fendrich K, Markus MRP, Baumeister SE, Doblhammer-Reiter G, Scholz RD, Hoffmann W. Future outpatient health-care utilization in an ageing population: projections up to the year 2020 based on the study of health in Pomerania(SHIP). J Public Health 2013;21(3):289-296.

9. Nilwik R, Snijders T, Leenders M, Groen BBL, Kranenburg JV, Verdijk LB, Loon LJCV. The decline in skeletal muscle mass with aging is mainly attributed to a reduction in type II muscle fiber size. Exp Gerontol 2013;48(1):492-498.

10 Landi F, Liperoti R, Fusco D, Mastropaolo S, Quattrociocchi D, Proia A, Tosato M, Bernabel R, Onder G. Sarcopenia and Mortality among Older Nursing Home Residents. J Am Med Dir Assoc 2012;13(2):121-126.

11. Carter CS, Marzetti E, Leeuwenburgh C, Manini T, Foster TC, Groban L, Scarpace PJ, Morgan D. Usefulness of Preclinical Models for Assessing the Efficacy of Late-Life Interventions for Sarcopenia. J Gerontol A Biol Sci Med Sci 2012;67(1):17-27.

12. Sayer AA, Robinson SM, Patel HP, Shavlakadze T, Cooper C. Grounds MD.[REMOVED HYPERLINK FIELD] New horizons in the pathogenesis, diagnosisand management of sarcopenia. Age Ageing 2013;42(2):145150.

13. Arnold P, Bautmans I. The influence of strength training on muscle activation in elderly persons: A systematic review and meta-analysis. Exp Gerontol 2014;58(1):58-68.

14. Hilde L, Torstveit MK, Anderssen SA. Traditional versus functional strength training: effects on muscle strength and power in the elderly. J Aging Phys Act 2013;21(1):51-70.

15. Stewart VH, Saunders DH, Greig CA. Responsiveness of muscle size and strength to physical training in very elderly people: A systematic review. Scand J Med Sci Sports 2013;24.

16. Solberg PA, Kvammeb NH, Raastad T, Ommundsena $\mathrm{Y}$, Tomtenb SE, Halvaria $\mathrm{H}$, Lolandc NW, Hallénb J. Effects of different types of exercise on muscle mass, strength, function and well-being in elderly. Eur J Sport Sci 2013;13(1):112-125.

17. Regterschot GR, Folkersma M, Zhang W, Baldus H, Stevens M, Zijlstra W. Sensitivity of sensor-based sit-to-stand peak power to the effects of training leg strength, leg power and balance in older adults. Gait Posture 2014;39(1):303-307.

18. Hasselgren L, Olsson LL, Nyberg L. Is leg muscle strength correlated with functional balance and mobility among inpatients in geriatric rehabilitation? Arch Gerontol Geriatr 2011;52(3):220-225.

19. Pérez VSC, Haas AN, Wolff SS. Analysis of activities in the daily lives of older adults exposed to the Pilates Method. J Bodywork Mov Ther 2013;17.

20. Vieira FT, Faria LM, Wittmann JI, Teixeira W, Nogueira LAC. The influence of Pilates method in quality of life of practitioners. J Bodywork Mov Ther 2013;17(4):483-487.

21. Wells $C$, Kolt GS, Bialocerkowski A. Defining Pilates exercise: A systematic review. Complement Ther Med 2012;20(4):253-262.

22. Luz MA, Costa LOP, Fuhro FF, Manzoni ACT, Oliveira NTB, Cabral CMN. Effectiveness of mat Pilates or equipment-based Pilates exercises in patients with chronic nonspecific low back pain: a randomized controlled trial. Phys Ther 2014;16.

23. Appell IPC, Pérez VR, Nascimento MM, Coriolano HJA. The Pilates Method to Improve Body Balance in the Elderly. Arch Exerc Health Dis 2012;3(3):188-193.

24. Mokhtari M, Nezakatalhossaini M, Esfarjani F. The Effect of 12-Week Pilates Exercises on Depression and Balance Associated with Falling in the Elderly. Procedia Soc Behav Sci 2013;70(25):1714-1723.

25. Kolyniak IEGG, Cavalcanti SMB, Aoki MS. Avaliação isocinética da musculatura envolvida na flexão e extensão do tronco: efeito do método Pilates. Rev. Bras Med Esp 2004;10(6):487-490.
26. Oliveira LC, Oliveira RG, Pires-Oliveira DAA. Effects of Pilates on muscle strength, postural balance and quality of life of older adults: a randomized, controlled, clinical trial. J. Phys Ther Sci 2015; 27:871-876.

27. Misic MM, Valentine RJ, Rosengren KS, Woods JA, Evans EM. Impact of training modality on strength and physical function in older adults. Gerontology 2009;55(4):411-416.

28. Lipschitz DA. Screening for nutritional status in the elderly. Prim Care 1994;21:55-67.

29. Hughes MA, Duncan PW, Rose DK, Chandler JM, Studenski SA. The relationship of postural sway to sensorimotor function, functional performance, and disability in the elderly. Arch Phys Med Rehabil 1996;77:567-572.

30. Stumbo TA, Merriam S, Nies K, Smith A, Spurgeon D, Weir JP. The effect of hand-grip stabilization on isokinetic torque at the knee. J Strength Cond Res 2001;15(3):372-377.

31. Bottaro M, Russo AF, Oliveira RJ. The effects of rest interval on quadriceps torque during an isokinetic testing protocol in elderly. J Sports Sci Med 2005;4:285-290.

32. Kong PW, Burns SF. Bilateral difference in hamstrings to quadriceps ratio in healthy males and females. Phys Ther Sport 2010;11(1):12-17.

33. Wright J, Ball N, Wood L. Fatigue, H/Q ratios and muscle coactivation in recreational football players. Isokinet Exerc Sci 2009;17(3):161-167.

34. Coombs R, Garbutt G. Developments in the use of hamsting/quadriceps ratio for the assessement of muscle balance. J Sports Sci Med 2002; 1(3):56-62.

35. Borg GAV. Psychophysical bases of perceived exertion. Med Sci Sports Exerc 1982;14(5):377-381.

36. Di Lorenzo CE. Pilates: what is it? Should it be used in rehabilitation? Sports Health 2011;3(4):352-361.

37. Teixeira J, Carvalho P, Moreira C, Santos R. Isokinetic Assessment of Muscle Imbalances and Bilateral Differences between Knee Extensores and Flexores' Strength in Basketball, Footbal, Handball and Volleyball Athletes. International Journal of Sports Science 2014;4(1):1-6.

38. Patsika G, Kellis E, Kofotolis N, Salonikidis K, Amiridis IG. Synergetic and antagonist muscle strength and activity in women with knee osteoarthritis. Journal of Geriatric Physical Therapy 2014;37(1):17-23.

39. Dias JMD, Arantes PM, Alencar MA, Faria JC, Machala CC, Camargos FF, Zazá DC. Relação isquiotibiais/quadríceps em mulheres idosas utilizando o dinamômetro isocinético. Rev Bras Fisioter 2004;8(2):111-115.

40. Karatrantoua K, Gerodimos V, Dipla K, Zafeiridis A. Whole-body vibration training improves flexibility, strength profile of knee flexors, and hamstrings-to-quadriceps strength ratio in females. J Sci Med Sport 2013;16(1):477-481.

41. Lopes L, Dalmut AB, Azevedo LS, Valério V, Coppatti N, Bona CC. Pico de torque e relação isquiotibiais/quadríceps de idosas praticantes de ginástica em dois grupos de convivência no contexto Passo Fundo - RS. Rev Bras Ciên Env Hum 2010;7(1):42-51.

42. Loturco I, Ugrinowitsch C, Roschel H, Tricoli V, González-Badillo JJ. Training at the optimum power zone produces similar performance improvements to traditional strength training. J Sports Sci Med 2013;12(1):109-115.

43. Locks RR, Costa TC, Koppe S, Yamaguti AM, Garcia MC, Gomes AR. Effects of strength and flexibility training on functional performance of healthy older people. Braz J Phys Ther 2012;16(3):184-190.

44. Melo MO, Gomes LE, Silva YO, Bonezi A, Loss JF. Assessment of resistance torque and resultant muscular force during Pilates hip extension exercise and its implications to prescription and progression. Braz J Phys Ther 2011;15(1):23-30. 